\title{
Incommunicado detention and torture in Spain, Part IV: Psychological and psychiatric consequences of ill-treatment and torture: trauma and human worldviews ${ }^{i}$
}

\author{
Miguel Angel Navarro-Lashayas, PhD*, Pau Pérez-Sales, MD, PhD**, Gabriela Lopez- \\ Neyra,*** Maitane Arnoso Martínez, PhD****, Benito Morentin, MD, PhD*****
}

\begin{abstract}
Background: Most literature on psychological consequences of torture is related to prolonged detention. Psychological consequences of intensive physical and psychological torture in brief detention have not been investigated. The aim of this study is to analyse the psychological impact of torture in short-term incommunicado detention.
\end{abstract}

Method: A sample of 45 Basque people who had allegedly been subjected to ill-treatment or torture whilst held in incommunicado detention between two and 11 days in Spain in the period 1980-2012 was analysed. The period between detention and evaluation ranged between two and 12 years. Each case was evaluated by several psychiatrists and psychologists. Clinical interviews which

\footnotetext{
*) Human Rights Section, Spanish Association of Neuropsychiatry (AEN).

${ }^{\star \star}$ ) SiR[a] Centre, GAC Community Action Group and Hospital La Paz, Spain.

$\star \star \star$ ) GAC - Community Action Group, Resource Centre on Mental Health and Human Rights, Spain.

$\star \star \star \star)$ University of the Basque Country.

$\star \star \star \star \star)$ ARGITUZ - Human Rights Association and

Section of Forensic Pathology, Basque Institute of Legal Medicine, Spain.
}

Correspondence to: navarro.miwel@gmail.com

${ }^{\text {i }}$ Editor: Lilla Hárdi. followed the Istanbul Protocol were assessed, as were psychometric tests (Post-traumatic Checklist-Civilian version (PCL-C), Beck Depression Inventory (BDI) and Vital Impact Assessment Questionnaire (VIVO)) and external documentary evidence. A cumulative prevalence of psychiatric diagnosis (ICD-10) from the period of detention was established.

Findings. Post-traumatic stress disorder (PTSD) was the most frequent diagnosis (53\%). Enduring personality change after a catastrophic experience was detected in $11 \%$ of subjects. Other diagnoses were depressive disorders (16\%) and anxiety disorders (9\%). Psychometric evaluation at the time of the study showed symptoms of PTSD in $52 \%$ of the subjects (with a tendency for these symptoms to diminish over time) and depressive symptoms in $56 \%$. The VIVO questionnaire discerned two subgroups of survivors: "affected" survivors (36\%); and "resilient" survivors (64\%).

Interpretation. The data demonstrated two important issues: the undervalued damaging effect of intensive torture in short-term detention and the long lasting psychological damage of the same over time.

Keywords: Psychological torture, incommunicado detention, posttraumatic stress disorder. 


\section{Introduction}

Torture may result in serious long-term psychological sequelae, including permanent changes in identity and worldviews, and clinical sequelae such as post-traumatic stress disorder (PTSD) and depression. ${ }^{1-9}$ This information is mostly based on studies with survivors who have suffered torture during periods of prolonged detention. The psychological impacts of torture in shortterm detention have received less attention. At first glance, it might be expected that the consequences of torture in time-limited detention should be milder than in longer periods of detention, but this is not the impression given to organizations working with survivors. Contemporary torture is becoming more psychological in western societies. Clinical research on torture shows that the perceived severity of psychological torture is a better predictor of PTSD than the perceived severity of physical torture. ${ }^{9}$

Spanish anti-terrorist legislation allows incommunicado detention for a period of five days with the possibility of extending detention to 13 days. As we concluded in Part II, contemporary short-term ill-treatment and torture mostly relies on the use of intensive psychological techniques in combination with physical ones. These methods, applied during a relatively short detention period, are aimed at breaking the resistance of the victim to obtain information or self-incrimination. To our knowledge, there are no studies on the psychological impact of torture in short-term detention and in western settings where torture is mainly psychological.

\section{Methods}

We examined a stratified purposive sample of Basque people $(\mathrm{N}=45)$ who reported ill-treatment or torture while held in incommunicado detention for an average of five days between
1980 and 2012 in Spain. The participants and the methods of collecting data were the same as set out in Part I and II.

\section{Instruments and procedure}

The protocol included a complex system of forensic psychological examinations and psychometric measurements. Each case was assessed by two clinical psychologists or psychiatrists who conducted extensive clinical interviews (following the Istanbul Protocol). The report was then contrasted with psychological tests and external sources of data (i.e. psychiatric, psychological or medical reports) by independent researchers who had not seen the initial findings.

\section{Psychometric tests}

The following self-ratings tests were included:

Post-traumatic Checklist - Civilian Version $(P C L-C)^{10}$

The PCL-C is a 19-item scale that follows the diagnostic criteria for PTSD in DSM-IVR. Each item corresponds to a symptom, which is evaluated in frequency and intensity on a scale from 1 to 4 . There are four cut-off points recommended according to the original validation studies: ${ }^{11}$ Less than 44 points = Absence of PTSD $; 45-50=$ Symptoms of PTSD (or Partial Syndrome); 51-55= Likely Presence of PTSD; More than 55= Diagnosis of full PTSD.

\section{Beck Depression Inventory (BDI1) ${ }^{12}$}

The BDI is the most widely used scale for quantifying depressive symptoms. It evaluates primarily clinical symptoms of melancholy and intrusive thoughts present in depression. The test has 21 items on a scale from 0 to 3 . The recommended cut-off points are: 0-9 = Absence of depression; 10-16 = Mild depression; 17-29 = Moderate depression; $30-63=$ Severe depression. ${ }^{13}$ 


\section{Vital Impact Assessment Questionnaire $(\text { VIVO })^{14}$}

This questionnaire assesses the impact of traumatic experiences on the perception of the self, others and the world as well as the impact on the subject's emotions and beliefs. It has been validated through a multi-sample collaborative international study conducted in 13 countries, including survivors of torture from Spain, Argentina and Uruguay.

All of the participants filled in the VIVO Questionnaire. PCL-C and BDI were used only when the psychiatrists or psychologists considered it necessary to refine the diagnosis.

\section{Statistical analysis}

Data was processed with SPSS 17 and ATLAS 6.0 statistical software for quantitative and qualitative variables respectively. We used descriptive statistics (means and standard deviations, or numbers and percentages) for all measures. Additionally, the VIVO questionnaire was used to identify resilient versus less resilient survivors according to the severity of symptoms through a SPSS k=2 Cluster Analysis Procedure. The two groups were then compared using a Discriminant Analysis, based on membership of the resilient or less resilient group as the dependent variable and the subscales of VIVO as independent variables. The values of VIVO, PCL-C and BDI were compared over time using chi-square contingency tables for frequencies and Kruskal-Wallis tests for means. Additionally, a qualitative analysis was conducted using a thesaurus of terms derived from the Istanbul Protocol (see Part III).

\section{Results}

The sociodemographic and socio-political characteristics of the sample, the assessment of credibility, and the analysis of torture methods were set out in Part II and III.

\section{Psychiatric diagnoses}

Table 1 shows the cumulative prevalence of psychiatric diagnosis (ICD-10) from the moment of detention, according to clinical assessments. The data does not include pre-existing conditions unless there was a clear deterioration in those conditions following arrest.

PTSD (53\%) was by far the most frequent diagnosis. In total, $76 \%$ of survivors had some kind of stress or adjustment disorder. This was followed by those with depressive disorders (16\%); personality disorders (13\%); and anxiety disorders (9\%) (Table 1).

The most severe diagnosis associated with traumatic experiences in ICD-10 is 'Enduring personality change after a catastrophic experience' (EPCACE, F62.0). This suggests permanent damage which was not present before the pathogenic experience, with a significant transformation of personality, often associated with rigid and maladaptive behaviour. The diagnosis is essentially based on the presence of a permanent attitude of distrust or hostility towards the world; social isolation; feelings of emptiness or hopelessness; the constant feeling of 'being on edge' as if constantly threatened; or a sense of self-estrangement. In our sample, $11 \%$ of the examinees fall into this extreme form of damage.

\section{Symptoms of post-traumatic stress disorder (PCL-C)}

29 of the 45 subjects completed the PCL-C. At the time of the forensic examination, approximately a quarter had full or possible PTSD and another quarter had some symptoms of PTSD (Table 2).

Table 2 presents the data organized by the time elapsed since detention and the forensic examination. The data suggests, although unconfirmed by statistical results, 
Table 1: $I C D-10$ psychiatric diagnosis $(N=45)^{\mathrm{i}}$

\begin{tabular}{|c|c|}
\hline & $\mathbf{N}(\%)$ \\
\hline Depressive disorder & $7(16 \%)$ \\
\hline F32.0 Depressive disorder - Mild & 3 \\
\hline F32.1 Depressive disorder - Moderate & 2 \\
\hline F33.1 Depressive disorder - Recurrent & 1 \\
\hline F33.3 Depressive disorder - Severe (with psychotic symptoms) & 1 \\
\hline Phobic disorders & $1(2 \%)$ \\
\hline F40.2 Specific (isolated) phobias & 1 \\
\hline Anxiety disorders & $4(9 \%)$ \\
\hline F41.1 Generalized anxiety disorder & 2 \\
\hline F41.2 Mixed anxiety and depressive disorder & 1 \\
\hline F41.9 Anxiety disorder, unspecified & 1 \\
\hline Obsessive-compulsive disorder & $2(4 \%)$ \\
\hline F42.0 Predominantly obsessional thoughts or ruminations & 2 \\
\hline Reaction to severe stress, and adjustment disorders & $34^{\star}(76 \%)$ \\
\hline F43.0 Acute stress reaction & 3 \\
\hline F43.1 Post-traumatic stress disorder & 24 \\
\hline F43.2 Adjustment disorders & 6 \\
\hline F43.9 Reaction to severe stress, unspecified & 2 \\
\hline Somatoform disorders & $2(4 \%)$ \\
\hline F45.8 Other somatoform disorders & 1 \\
\hline F45.9 Somatoform disorder, unspecified & 1 \\
\hline Disorders of adult personality and behaviour & $6(13 \%)$ \\
\hline F60.7 Dependent personality disorder & 1 \\
\hline F62.0 Enduring personality change after a catastrophic experience & 5 \\
\hline No psychiatric pathology & $6(13 \%)$ \\
\hline Z65.4 Victim of torture who does not meet criteria for any ICD-10 & 6 \\
\hline
\end{tabular}

${ }^{\mathrm{i}}$ Please note: Some people have more than one diagnosis, so the sum of percentages exceeds $100 \%$

that there is an improvement of PTSD symptoms with time. For most people there is a progressive, albeit slow control of traumatic symptoms. (Mean < 2 yrs: 45; 3-8 yrs: 45; > 8 yrs : 35; K-W: 0.182, n.s.).

In Table 3 the frequency of each PTSD symptom is shown with selected quotations from the survivors. The most frequent symptoms were related to the avoidant cluster (feeling bad about remembering the experience (54\%), truncated future (33\%) and physical reactions recalling the experience (30\%) for example); and the hyperreactivity cluster (hyper-arousal or remaining on guard (42\%) and restless or startled
$(30 \%))$. Probably due to the time elapsed since detention, re-experimentation symptoms were less frequent, which include painful memories, thoughts or images (36\%) and having sleep problems/nightmares (34\%).

\section{Depression symptoms: BDI}

The BDI was completed by 32 subjects (Table 2). At the time of the assessment, depression was rated as mild in a quarter, and as moderate or severe in one third of survivors. The mean BDI values did not change significantly with time (Mean $<2$ yrs: 12; $3-8$ yrs: 12 ; $>8$ yrs: 13.9 ; K-W : 0.745 ; 
Table 2: Post-traumatic stress disorder (PCL-C), Beck Depression Inventory (BDI) and Vital Impact Assessment Questionnaire (VIVO) scores across time since detention

\begin{tabular}{|c|c|c|c|c|}
\hline & $\begin{array}{l}\text { Less than } 2 \\
\text { years }\end{array}$ & $\begin{array}{l}\text { Between } 3 \text { and } \\
7 \text { years }\end{array}$ & $\begin{array}{l}\text { More than } 8 \\
\text { years }\end{array}$ & TOTAL \\
\hline \multirow[t]{2}{*}{ PCL-C } & $N=6$ & $N=8$ & $\mathrm{~N}=15$ & $\mathrm{~N}=\mathbf{2 9}$ \\
\hline & $\mathrm{n}(\%)$ & $\mathrm{n}(\%)$ & $\mathrm{n}(\%)$ & $\mathrm{n}(\%)$ \\
\hline Absence of PTSD & $1(17)$ & $4(50)$ & $10(67)$ & $15(52)$ \\
\hline Symptoms of PTSD & $3(50)$ & $1(12)$ & $3(20)$ & $7(24)$ \\
\hline Possible PTSD & $2(33)$ & $1(12)$ & $1(7)$ & $4(14)$ \\
\hline PTSD & 0 & $2(25)$ & $1(7)$ & $3(10)$ \\
\hline \multirow[t]{2}{*}{ BDI } & $\mathbf{N}=7$ & $N=9$ & $\mathrm{~N}=16$ & $\mathrm{~N}=32$ \\
\hline & $\mathrm{n}(\%)$ & $\mathrm{n}(\%)$ & $\mathrm{n}(\%)$ & $\mathrm{n}(\%)$ \\
\hline Absence of depression & $3(43)$ & $5(56)$ & $6(37)$ & $14(44)$ \\
\hline Mild depression & $2(29)$ & $3(33)$ & $3(19)$ & $8(25)$ \\
\hline Moderate depression & $2(29)$ & 0 & $6(37)$ & $8(25)$ \\
\hline Severe depression & 0 & $1(11)$ & $1(6)$ & $2(6)$ \\
\hline \multirow[t]{2}{*}{ VIVO } & $N=13$ & $N=9$ & $\mathrm{~N}=23$ & $\mathrm{~N}=45$ \\
\hline & $\mathrm{n}(\%)$ & $\mathrm{n}(\%)$ & $\mathrm{n}(\%)$ & $\mathrm{n}(\%)$ \\
\hline Major affectation & $5(38)$ & $2(22)$ & $9(31)$ & $16(36)$ \\
\hline Resilient & $8(61)$ & $7(78)$ & $14(61)$ & $29(64)$ \\
\hline
\end{tabular}

n.s). The most frequent depressive symptoms were 'changes in sleep patterns' and 'difficulty in concentration' (Table 4).

\section{Impact on identity and worldview: VIVo questionnaire}

The results of the VIVO questionnaire showed that mean values of the VIVO subscales did not differ from normative values in the general population, and that there were dissimilar results among individual survivors. In order to capture this variance and individualize subgroups of survivors, a cluster analysis was performed. Optimal classification was conducted with a twogroup solution ('affected' survivors $(n=16)$ and 'resilient' survivors $(n=29)$. The resulting function had a canonical correlation of 0.87 , with auto-values of 2.54 and a
Wilks' Lambda coefficient of 2.28 (4 d.f., p $<0.000$ ) indicating a robust result.

The subscales of the VIVO that contributed most to explain the differences between groups through a Discriminant Analysis were explored, again using group (Affected vs Resilient) as the independent variable and the dimensions of the VIVO as dependent variables (Table 5). The group of survivors with damaged worldviews had significantly higher scores in 'identity - perception as a victim', 'negative worldview' and 'negative perception of future'. They also perceived less 'support from society' and feelings that they were 'blamed by others' for what happened to them. They tended to report that they felt 'frozen' when something serious happened to them, a greater tendency to ruminate about what happened, to have non-specific fears of 
Table 3. Symptoms of post-traumatic stress disorder (PCL-C) at the time of the study. Quantitative and qualitative data $(N=29)$

\begin{tabular}{|c|c|c|}
\hline PTSD symptoms & $\%$ & Qualitative data \\
\hline \multicolumn{3}{|l|}{ Re-experiencing } \\
\hline Painful memories, thoughts or images & 36 & "Things happen to me that don't make any sense, \\
\hline Repeated nightmares & 9 & which are like weird, aren't they? For example, \\
\hline $\begin{array}{l}\text { Behaviour or feeling as if the event was } \\
\text { happening all over again }\end{array}$ & 6 & $\begin{array}{l}\text { like when I was arrested, I was tied with a bridle- } \\
\text { type thing. I could not see very well. At the begin- } \\
\text { ning, I did not realize it was because of that, a } \\
\text { piece of plastic that doesn't mean anything, but } \\
\text { you realize that it is because of that." } \\
\text { "Lots of nightmares, even now in some dreams } \\
\text { the Guardia Civil come in. More in the first few } \\
\text { months." }\end{array}$ \\
\hline
\end{tabular}

\section{Avoidance}

Feeling bad about remembering the experience Physical reactions recalling the experience Avoid talking or remembering the experience Avoid activities that remind the person of the experience

\section{Emotional anaesthesia}

Troubles remembering some parts of the experience

Loss of interest in things that used to interest him/her

Feeling distant from people

Emotionally blocked ("numb")

Truncated future

"What is here (referring to his head) forms a block and wants to forget and so there are things I do

27 not remember, right? Because there has been this

18 attempt to want to forget."

21 "You can be with a hundred people but are alone, which is what happens to me. I can be with a lot

24 of people but I am in my own world, I'm out of it." "I do remember that with the passage of time I

29 had things that were not in order, the first time I

3 put some order to them was when I left prison

33 and had to go to a psychologist... As I recounted some disjointed facts, somehow I skipped one day, or one fact, in those five days."

\section{Hyper-arousal}

Sleeping problems

Irritable, angry outbursts

Difficulty in concentrating

Hyper-arousal or remaining on guard

Restless or startled

\section{Functional criteria}

Perceived stress level above 5 (scale 1-10) Level of daily routines affectation above 5 (scale 1-10)

34 "I always look all around me, even when I go into

12 a bar for a coffee, I will never turn my back to the

3 door, I need to control my surroundings."

42 "I can hardly sleep, there is a noise and I wake up.

30 Before... I could fall asleep even if the building opposite my house collapsed; I didn't care."

41 "So far I've worked in hostelry, in the family bar

29 (...) with clients who you know more or less (...) now I have to relate to all kinds of people (...) and I could hardly think (...) I get very dizzy, I have to do it but don't know how to." 
Table 4: Beck Depression Inventory (BDI): main symptoms at the time of the study (N=32).

\begin{tabular}{lllll}
\hline Item & \multicolumn{3}{c}{ Severity scale (\%) } \\
& Absent & Mild & Moderate & Severe \\
\hline Loss of pleasure & 47 & 35 & 15 & 3 \\
Self-criticism & 35 & 59 & 6 & 0 \\
Agitation & 35 & 56 & 3 & 6 \\
Loss of interest & 50 & 41 & 9 & 0 \\
Changes in sleeping patterns & 29 & 41 & 15 & 15 \\
Irritability & 53 & 35 & 9 & 3 \\
Difficulty in concentration & 29 & 47 & 18 & 6 \\
Loss of interest in sex & 62 & 18 & 18 & 3 \\
\hline
\end{tabular}

Table 5: Vital Impact Assessment Questionnaire (VIVO). Cluster centres. Comparison of mean values between 'affected' and 'resilient' survivors

$\begin{array}{llll}\begin{array}{l}\text { Major affecta- } \\ \text { tion }(n=16)\end{array} & \begin{array}{l}\text { Resilient } \\ (n=29)\end{array} & F & \text { SIG }\end{array}$

\section{Worldview}

Negative worldview

63

Life lacks meaning

Ideological or religious convictions do not help

\section{Attitudes towards the world}

Suicide is an acceptable option

Fate is important in life

Not tolerating ambiguity and uncertainty

52

52

52

48

50

Search for the logic of facts

Vision of human being

Sharing the experience is useless

Suffering is useless

It is not possible to believe in the goodness of people

Loss of confidence in people

Unable to communicate the horror

Expression of suffering in dreams

\section{Coping}

Tendency to think about what happened - rumination 55

Frozen sensation during the events

Unable to forget

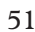

47

49

49

45

50

51

45

47

51

46

49

48

51

51

55
28,591,000

5,017 ,030

2,185 , 147

1,901 , 175

$1,100 \quad, 300$

,014 ,907

$5,455 \quad, 024$

$1,889 \quad, 177$

4,244, 046

635 ,430

5,404 ,025

2,796 ,102

3,392,073

4,337,043

29,882,000

,634 ,430 


\section{Impact of the past}

Experiences of guilt

55

Loss of self-confidence

Unable to learn from the facts.

Unable to change their way of being:

Nonspecific fears

\section{Emotions}

Negative emotions associated with the events

Feelings of helplessness

Rejection of negative feelings

\section{Narrating the experience}

Giving social testimony is unimportant

Communicating what happened is unimportant

\section{Consequences}

Lack of empathy - insensitivity to other victims

Decreased ability to love others

Questioning by chance - why me

\section{Identity}

Lack of social support

Feeling that society blames the victim

Negative future - no hope

Changes in identity since the facts

Changing priorities in life

Identity - victimhood determines outlook

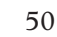

50

46

45

49

50

50

46

48

51

47

46

40

42

50

49

49

47

46
7,394 ,009

$1,033 \quad 315$

$13,420 \quad, 001$

1,203 279

10,517 ,002

,689 ,411

,737 395

6,983 ,012

,273 604

13,907 ,001

,895 ,350

$1,189 \quad 282$

,564 ,457

$\begin{array}{rr}17,690 & , 000 \\ 3,698 & , 061 \\ 17,498 & , 000 \\ 6,266 & , 016 \\ , 241 & , 626 \\ 12,086 & , 001\end{array}$

disorders, $11 \%$ enduring personality changes, and $9 \%$ anxiety disorders. ${ }^{i}$ High co-morbidity of depression and PTSD is well-documented in traumatized refugees: in the sample, $86 \%$ of patients with depressive disorder had also been diagnosed with PTSD.

Our findings are consistent with studies showing that the most common symptoms after torture are psychological, and include

${ }^{\mathrm{i}}$ The categories are not mutually exclusive. 
depression, anxiety, emotional instability, reduced ability to sleep, nightmares, and concentration and memory deterioration. ${ }^{2,4}$, ${ }^{15}$ A meta-analysis ${ }^{5}$ of 181 epidemiological studies on tortured populations from 40 countries found that the prevalence of PTSD and depression had large variability: $0 \%-$ 99\% for PTSD and 3\% - 85.5\% for depression. The average prevalence was $30 \%$ for PTSD and for depression. This high variability is largely due to the wide criteria used in the selection of participants and the instruments used for assessment. ${ }^{6}$ In a second meta-analysis ${ }^{7}$ of adult survivors of war and torture, the study found a high prevalence of psychological symptoms (anxiety, depression, irritability/aggressiveness, emotional liability, self-isolation/social withdrawal), cognitive symptoms (confusion/ disorientation, memory and concentration impairment, impaired reading ability), and neurovegetative symptoms (lack of energy, insomnia, nightmares, sexual dysfunction), ${ }^{8}$ but relatively low rates of full PTSD.

The present study suggests that people held under incommunicado detention usually recover from the experience of torture, but between $11 \%$ (based on ICD-10 diagnosis of Enduring Personality Change) and $36 \%$ (according to the cluster analysis of the VIVO questionnaire) have long-lasting damage.

This study is not longitudinal, and thus does not address the subject's evolution over time. However, considering that torture occurred on average 10 years prior to the assessment, we can conclude that torture has changed the lives of these subjects significantly. Our research does not clarify whether this is due to pre-existing vulnerability, to the experience of torture, or to other factors. The majority of subjects had also experienced other types of trauma before and after their alleged torture, for example (see Part II).
This included being politically repressed as a Basque dissident as well as persecuted and imprisoned. Further studies are needed to determine the role of each factor in the psychological health of the victim.

At the time of examination, $24 \%$ of interviewees were diagnosed with PTSD or possible PTSD using psychometric criteria despite the assessments taking place an average of 10 years after the period of detention. Even without full or possible PTSD, many subjects suffered from partial symptoms, such as feeling bad when recalling the traumatic events, hyperarousal, painful memories, loss of interest in things that they used to enjoy or feelings of truncated future.

Mean PTSD scores decreased with time suggesting that there is a progressive, though slow, improvement of symptoms. On the contrary, mean depressive scores increased with time suggesting a long-standing damage in emotions and affect.

Opponents to the use of PTSD in conjunction with torture victims consider that survivors experience a normal reaction to an abnormal stressor in the context of an abnormal social situation. ${ }^{16}$ Labelling torture symptoms as a mental disorder can be viewed as medicalizing a socio-political problem and individualizing social suffering. ${ }^{17}$ The emphasis is then not on symptoms but on the way the survivor reconceptualizes life. For example, how he or she reconsiders priorities in life, provides meaning to a devastating experience, builds a new positive identity and adjusts his or her perceptions of others and of the world. In our sample of 45 survivors, and according to the results of the VIVO questionnaire, about a third of the examinees have serious difficulties in reconceptualizing life.

Our results must be considered with caution. As most studies with torture 
survivors, our sample is small and purposive and the results cannot be extrapolated to other survivors in the Basque Country, especially those who have never spoken of their days under incommunicado detention. The use of self-report measures also tend to generate higher prevalence rates of PTSD and depression compared to clinical interviews. ${ }^{4,7}$

Despite the limitations of this study, the results show two important issues that deserve more detailed investigation: the undervalued damaging effect of intensive torture in short-term detention and the long-lasting psychological damage that can be detected over time.

\section{References}

1. Somnier FE, Genefke IK. Psychotherapy for victims of torture. Br J Psychiatry. 1986;149:323-9

2. Simpson M. Traumatic stress and the bruising of the soul: the effects of torture and coercive interrogation. In: Wilson JP, Raphael B, editors. International Handbook of Traumatic Stress Syndromes. New York: Plenum Press; 1993.

3. Petersen HD, Jacobsen P. Life-threatening torture without visible marks. Scand J Public Health. 1985;13:87-8.

4. Basoglu M, Paker M, Paker O, Ozmen E, Marks I, Incesu C, Sahin D, Sarimurat N. Psychological effects of torture: a comparison of tortured with nontortured political activists in Turkey. Am J Psychiatry. 1994;151:76-81.

5. Steel Z, Chey T, Silove D, Marnane C, Bryant
RA, Van Ommeren M. Association of torture and other potentially traumatic events with mental health outcomes among populations exposed to mass conflict and displacement: a systematic review and meta-analysis. JAMA. 2009;302:53749.

6. Fazel M, Wheeler J, Danesh J. Prevalence of serious mental disorder in 7000 refugees resettled in western countries: a systematic review. The Lancet. 2005;365:1309-14.

7. Johnson H, Thompson A. The development and maintenance of post-traumatic stress disorder (PTSD) in civilian adult survivors of war trauma and torture: A review. Clin Psychol Rev. 2008;28:36-47.

8. Basoglu M, Jaranson J., Mollica RF, Kastrup M. Torture and mental health: A research overview. In: Gerrity E, Keane TM, Tuma R, editors. The mental health consequences of torture. 2001. pp. 35- 62 .

9. Başoğlu M. A multivariate contextual analysis of torture and cruel, inhuman, and degrading treatments: Implications for an evidence-based definition of torture. Am J Orthopsychiatry. 2009; 79:135-145.

10. Weathers FW, Huska JA, Keane TM. The PTSD Checklist-Civilian Version (PCL-C). Boston: National Center for PTSD; 1991.

11. Ruggiero KJ, Del Ben K, Scotti JR, Rabalais AE. Psychometric properties of the PTSD Checklist-Civilian version. J Trauma Stress. 2003; 16:495-502.

12. Beck AT, Ward CH, Mendelson M, Mock J, Erbaugh JK. An inventory for measuring depression. Arch Gen Psychiatry. 1961;4:561-71.

13. Beck AT, Steer RA, Carbin MG. Psychometric properties of the Beck Depression Inventory: Twenty-five years of evaluation. Clin Psychol Rev. 1988;8:77-100.

14. Perez Sales P, Eiroa-Orosa FJ, Olivos P, Barbero-Val E, Fernández-Liria A, Vergara M. VIVO Questionnaire. A measure of human worldviews and identity in trauma, crisis and loss. Validation and preliminary findings. Journal of Loss and Trauma; 2012 DOI: 10.1080/15325024.2011.616828

15. Başoğlu M, Livanou M, Crnobarić C. Torture vs other cruel, inhuman, and degrading treatment: is the distinction real or apparent? Arch Gen Psychiatry. 2007;64:277-85.

16. Reeler AP. Is torture a post-traumatic stress disorder?. Torture. 1994;4:59-63.

17. Summerfield D. A critique of seven assumptions behind psychological trauma programmes in waraffected areas. Soc Sci Med. 1999;48:1449-62. 


\section{Appendix 1}

\section{Content analysis of the VIVO questionnaire. Examples of most salient categories}

\section{Worldview}

"I feel a little strange in society. (...) I feel people are distant, they don't understand the context you have suffered (...) maybe I am the strange one... don't know."

\section{Attitudes toward the world}

"I think about them, they were psychopaths. You wonder about who he is, how many people he has done the same thing to, if he has a family and if he goes home quietly, feeling like a hero for doing what he does... I am curious to know who they are and I would like to know their stories.

\section{Attitudes toward society}

"You have to be with a person who has passed through the same thing you've passed through, if not, people just don't understand you. I can talk and tell you, and explain, but you will never understand what I've been through. That is what happened to us in prison and that is why you have a lot to do with the people there"

\section{Attitudes toward society}

"I have not talked in depth about this, I find it hard... with friends I have spoken about it, with those I trust a lot, but more in the form of facts, like anecdotes, like getting away from myself, as if in third person."

\section{Coping with facts}

"I was afraid of what they could do to me. I was also very nervous, I was blocked, scared and physically hurt and it had started my body aching."

"They come in and I have not gotten them out of my head."
"The physical aspect, it hurts, there are some days that you cannot walk, but the psychological aspect is one thing that still today I cannot cope with. It's very hard, very hard."

\section{View of humanity}

"I used to be more affectionate now it is hard for me to have physical contact, to show my feelings through physical contact; I used to give hugs and kisses to my friends... Now I cannot, it doesn't come out of me."

I see around me that people continue with their lives as if nothing has happened, it brings me a sense of despair. To see that people are like this, that they are so insensitive to certain things that exist."

\section{Social support}

"You feel, above all, that society judges you. The arrest is broadcast on TV and the information they gave didn't help that happen. In the final analysis, people will always think that you did do something or that you deserve it, and that's hard."

\section{Future}

"Now I take life from day to day, I do not have many goals, now I am content if I'm not getting fired from a job and that's it. My goal this year is to not lose my job, and that's how it goes."

\section{Changes in identity}

"There is a before and an after experiencing a traumatic event, something changes inside us, we don't relate the same, life values change, things that didn't matter 
before do now, or vice versa, something within changes."

"Honestly if I feel affected, I'm not denying it, yeah I'm emotionally affected... there has been a change in me and I sincerely believe that I'm paying for what has happened."

\section{Changes in militancy}

"I didn't know if it was good or bad for me (to develop political activities on torture victims), but the truth is that I had no strength, because I've noticed that I needed to heal, without knowing how and from what, and for a while I was just going to pursue that."

\section{Posttraumatic growth}

"Over time things go on healing, I would rather say that I have quite forgotten them, you give more importance or you look at other things that go on happening to you, then you leave the others back there." 